\title{
HYDRAULIC TECHNOLOGY AND UTILIZATION OF OCEAN WAVE POWER
}

\author{
Tomiji Watabe*, Hideo Kondo** \\ ${ }^{*}$ Mechanical Engineering \\ ${ }^{* *}$ Civil Engineering \\ Muroran Institute of Technology \\ Muroran, Japan
}

\section{ABSTRACT}

Utilization of ocean wave power is one of our dreams.

A system introduced here "Pendulor" has pendulums which resonate in the exciting wave motion and the pendulums drive a generator via hydrostatic drive system. He believe, this "Pendulor" mould bring the dream in our life. The combination of the pendulum (mechanical power transfer) and the HST (hydraulic power transfer ) gave $40 \%$ overall efficiency in ocean testing. having a basic matching of their huge thrust force - low speed features. The Pendulor absorbs wave force and makes little reflecting waves so effectively that the caisson attached it can become an improved breakwater.

25 yen $/ \mathrm{k}$ WH or 9.4 yen $/ \mathrm{kHH}$ are expected using a proto-type Pendulor designed here, including with or without caisson cost.

\section{KEY YOPDS}

Fluid Power System, 0cean Engineering, Systems Engineering, Power Plant.

\section{NOMENCLATURE}

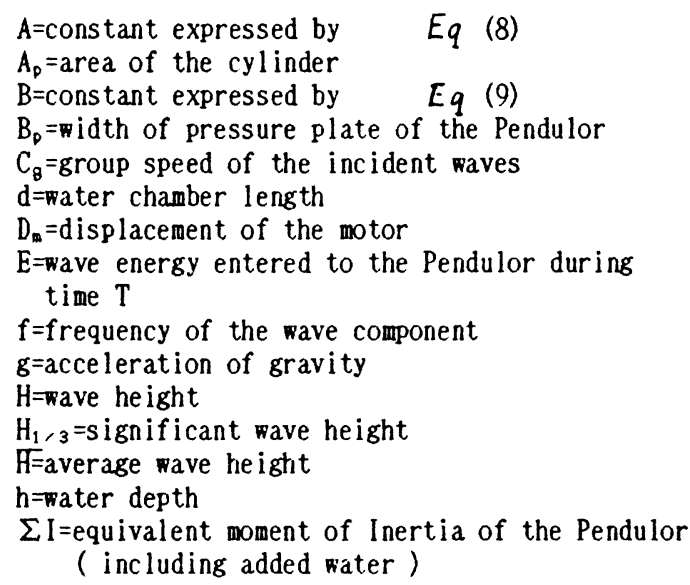

$\mathrm{K}=$ restoring coefficient due to water elevation behind the Pendulor

$\mathrm{K}_{\mathrm{c}}=$ constant

$K_{\mathrm{b}}=$ restoring coefficient of the Paendulor

$1=$ distance from the swing center to surface of still water

$M=$ amplitude of exciting moment

$M_{e}=$ reaction moment of the cylinder

$\overline{M_{B}}=$ average value of $M_{0}$

$N$ =damping coefficient due to radiation waves generated by the Pendulor

$N_{0}=$ equivalent linear damping coefficient by the cylinder

$\mathrm{n}=\mathrm{oil}$ motor speed

$P=$ wave power per meter crest

$\bar{p}=$ average cylinder pressure of the delivery period

$Q=$ average flow from the cylinder

$r=a r m$ length (see Fig. 1)

$S(f)=$ density function of frequency spectrum

$T=$ period of wave

$T=$ mean wave period

$T_{m}=$ average motor torque

$\mathrm{t}=\mathrm{time}$

$\mathrm{V}=0 \mathrm{il}$ volume trapped in the accumulator $W=e n e r g y$ absorbed by the cylinder during $T$

$\theta=$ ansular displacement of the Pendulor

$\theta_{\theta}=$ initial extreme value of $\theta$

$\theta_{a}=$ amplitude of the Pendulor

$\eta=$ energy absorption ratio

$\eta_{t}=$ torque efficiency

$\eta_{v}=$ volumetric efficiency

$\eta_{\mathrm{m}}=$ motor efficiency

$\rho=$ density of water

$\lambda=$ wave length

$\omega=c$ ircular frequancy of wave

\section{PREFACE}

The Problem in putting wave energy to practical use is whether the energy cost can be reduced to an acceptable level. In addition to the same excellent ability for wave power extraction as a modern machine, the system must be as simple as an ancient machine. How ever, it still seems difficult to find a way to reach a reasonable cost 
target al though many types of apparatuses have been proposed and studied in the world. ${ }^{1}$

A system combined with both a mechanecal device for receiving wave power and an oil-hydraulic device for converting the power to an electric devece has been developed by us. It is named the Pendulor system. By introducing hydraulic technology into the wave power utilizatiln system, we can propose more adaptable and more flexible system to harness the wild wave power. One of them is the Pendulor system. ${ }^{21}$

We have been studying it, including coastal operations for 10 years. Through our investigation, the system has proved its good reliability and high power extraction ratio using several test models featured by the design criterion developed at Muroran Inst. of Technology - The proto-type design of, and the study on, cost expectancy of the wave energy have been accomplished

\section{THE PENDULOR SYSTEM}

Wave energy consists of two kinds of physical energy:---potential and kinetic. The Pendulor directly aborbs the energy as the Pendulor's swinging motion. As illustrated in Fig. 1,

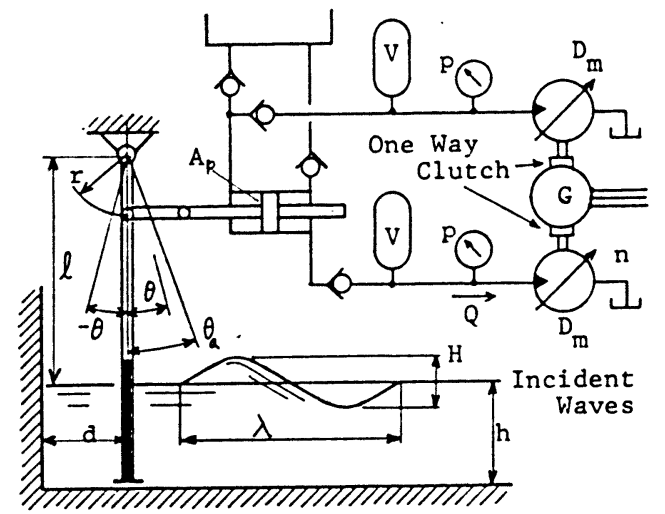

Fig. I Principle of the Pendulor System

incident waves are changed to standing waves by superposition with reflecting waves in the chamber - At the node of the standing waves, all energy is concentrated into horizontal reciprocating water flow. A pendulum with a pressure plate placed at the node "Pendulor", is driven by that flow. The Pendulor drives a cylinder, and then two hydraulic motors fed by the cylinder drive a generator. There is a phase difference of $\pi$ between the two motors. As a result al though the output torque of each motor varies periodically according to a wave's pause, the final output is made smooth by the superposition of the two. ${ }^{3}$ )

The energy absorption ratio can be predicted by the following procedure. The Pendulor's motion is found by solving the Pendulor's equation of motion expressed in Eq. (1)

$$
\begin{aligned}
\sum I \ddot{\theta}+N \dot{\theta}+\left(K_{\theta} \div K\right) \theta+M_{\theta} \\
=M \sin \omega t
\end{aligned}
$$

where $M_{\theta}$ is a reaction moment of the cylinder. It is written in the following form when the cylinder delivers oil to the circuits shown in Fig. 1.

$$
M_{\theta} \fallingdotseq-\left\{M_{02}+K_{c}\left(\theta-\theta_{0}\right)\right\}
$$

where $M_{0_{2}}$ is the initial value of the reaction moment.

For absorbing maximum energy, $M_{0}$ should satisfy the following Eq. ${ }^{4}$

$$
\mathrm{W}=\int_{0}^{T} M_{\diamond} \dot{\theta} \mathrm{dt}=\eta \int_{0}^{T} N \dot{\theta}^{2} \mathrm{dt}
$$

Furthermore, when the natural frequency of the Pendulor is adjusted to the same substantial value as the frequency of the standing raves, and when the Pendulor is hung vertically at the node, the cylinder absorbs almost all of the energy of the incident waves. ${ }^{5}$ So the energy absorbed during T can be expressed as Eq. (4), in which the right term means the incident energy coming into the Pendulor during $\mathrm{T}$.

En

$$
\begin{gathered}
=\frac{1}{4} \mathrm{~T} \mathrm{~B}_{\diamond}\left(\frac{\mathrm{H}}{2}\right)^{2} \rho \mathrm{g} \frac{\omega}{\mathrm{k}_{\theta}}\left(1+\frac{2 \mathrm{k}_{\mathrm{Q}} \mathrm{h}}{\sinh 2 \mathrm{k}_{\mathrm{B}} \mathrm{h}}\right) \eta \\
=\int_{0}^{\mathrm{T}} \mathrm{M}_{\diamond} \dot{\theta} \mathrm{dt}
\end{gathered}
$$

The wave number $k_{\theta}=2 \pi / \lambda$ must satisfy the dispersion relation $\omega^{2} / g=k_{\theta} \tanh \left(k_{Q} h\right)$. With this optimal condition, the Pendulor is resonated, so that the phase difference between the exciting moment $y \sin \omega t$ and $\theta$ is fixed in $(-\pi / 2)$. Since the Pendulor mostly absorbs the incident wave energy, it generates no reflecting waves. ${ }^{61}$

Fig. 2 shows the tipical results obtained in our laboratory using a $1 / 6$ scale model.

$$
\mathrm{T}=1.4 \mathrm{~s}, \quad \begin{aligned}
\nabla \mathrm{k}_{e}^{\prime} & =5.0 \times 10^{6} \mathrm{~N} / \mathrm{m} \\
\quad & =5.0 \times 10^{5} \mathrm{~N} / \mathrm{m} \\
O & =2.8 \times 10^{5} \mathrm{~N} / \mathrm{m}
\end{aligned}
$$

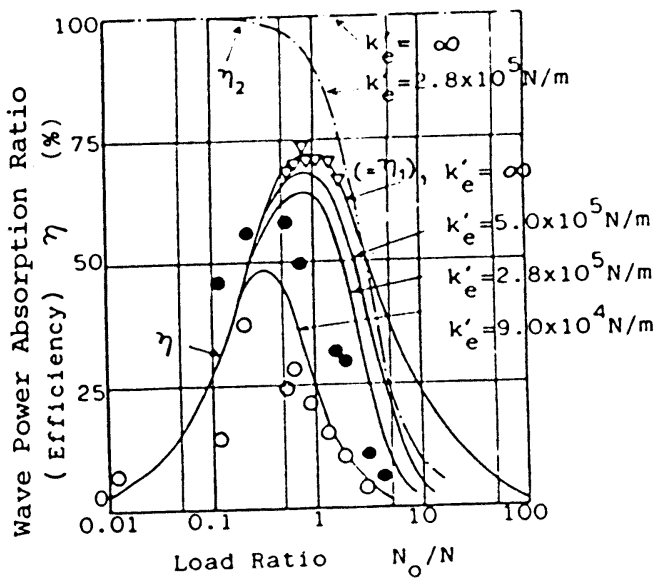

Fig. 2 Wave Power Absorption Ratio

\section{AN OPTIMAL DESIGN OF THE HYDRALLIC CIRCUITS}

In Chapter 2, the optimal condition for the Pendulor was explained when regular waves ( having constant wave height and period ) drive it. Next we have to consider the influences by the real open sea waves ( having irregular wave heights and periods ). 
Sea waves can be observed as superposition of many different waves. Using average wave height wave height $H$ is discribed as Rayleigh distribution in the following Eq. (5),

$$
\mathrm{p}(\mathrm{H} / \mathrm{H})=\frac{\pi}{2}\left(\frac{\mathrm{H}}{\mathrm{H}}\right) \exp \left[-\frac{\pi}{4}(\mathrm{H} / \mathrm{H})^{2}\right]
$$

where $p(H / B)$ is a probability density function of wave height,

Fig. 3 shows $p(H / A)$ versus $H / H$, while the function of wave period $T$ is also shown there in comparison with it, using mean wave period $T$.

The mean power per unit length of the wave crest $P$, was verified by Bretschneider \& Mitsuyasu as the Eq. (6). ${ }^{7}$

$$
\begin{aligned}
P & =\rho g \int_{0}^{\infty} C_{0} S(f) d f \\
& =0.441 \mathrm{H}^{2}{ }_{1 / 3} T_{1 / 3}
\end{aligned}
$$

$$
S(f)=A f^{-5} \text { exp }\left[-B f^{-4}\right]
$$

$A=0.257 \mathrm{H}_{1,3}^{2} \mathrm{~T}^{-4}{ }_{1 / 3}$

$B=1.03 T^{-41 / 3}$

Though the sea waves consist of a wide band of spectrum, Fig. 3 shows a peak distinguished in its distribution. Since the wave energy is concentrated around the peak component, a preferable energy absorption should be done as a regular wave operation, if the optimal condition is selected towards the peak. Any control devices controlling $M_{\theta}$ and natural frequency of the Pendulor, because mean wave height $B$ and mean wave periodT vary day by day.

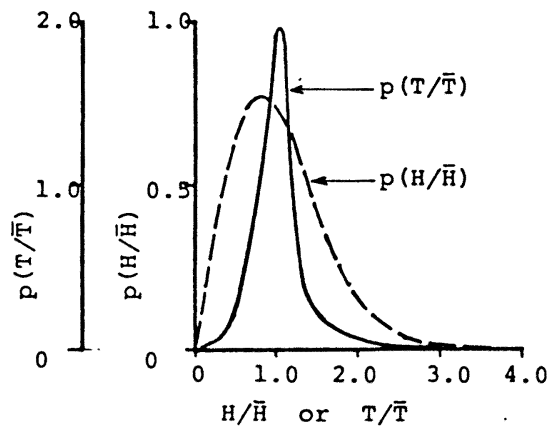

Fig. 3 Wave Spectra

At the optimal operation, the amplitude of the Pendulor $\theta_{\mathrm{a}}$ theoretically takes the value expressed by Eq. (10). ${ }^{8}$ )

$$
\theta_{a}=\frac{\mathrm{k}_{\theta} \mathrm{Z}_{\theta}}{4 \mathrm{Y}_{\theta} \sinh \left(\mathrm{k}_{\theta} \mathrm{h}\right)} \cdot \frac{\mathrm{H}}{2}
$$
are required to keep the optimal condition, by

$$
Z_{\theta}=\sinh \left(2 k_{\theta} h\right)+2 k_{\theta} h
$$

In order to maintain the optimal operation, the following procedure has been considered;

1) Reaction moment $M_{\theta}$ is controlled to keep the relationship between $\mathrm{H}$ and $\theta_{\mathrm{a}}$ expressed in Eq. (10).

2) This can be done by the energy conservation principle, if every energy absorbed by each stroke of the cylinder, mould substantially correspond to the every energy of the waves driving the Pendulor one after another.

Fig. 4 shows the content of the idea metioned above;--- it is a controlled moment $M_{0}$ which satisfies Eq. (3). The following equation can be written for the energy conservation.

$$
\mathrm{W}=2 \int_{\theta_{\mathrm{a}}}^{\theta_{\mathrm{a}}} \mathrm{M}_{\mathrm{o}} \mathrm{d} \theta=\eta \mathrm{E}
$$

where $\theta_{\mathrm{a}}$ is expressed by Eq. (10)

In Fig. 4, is shown as the area enclosed by $M_{0}$ curve, and so long as $\theta_{\mathrm{a}}$ is varied with $H_{\text {, }}$ the enclosures take form of triangles or rectangles. From Eq. (13), $M_{0}$ is discribed as follows.

$$
\mathrm{M}_{\theta}=\frac{\pi}{4} \omega \mathrm{N} \eta \theta_{\mathrm{a}}+\frac{\partial \mathrm{M}_{\mathrm{B}}}{\partial \theta} \cdot \theta \quad \text { when } \quad \dot{\theta}<0
$$

$$
\begin{aligned}
& M_{\theta}=-\frac{\pi}{4} \omega N \eta \theta_{0}+\frac{\partial M_{\theta}}{\partial \theta} \cdot \theta \text { when } \dot{\theta}>0 \\
& \text { where } \quad \theta_{0} \geqq \theta \geqq-\theta_{0} \\
& M_{\theta 2}=-M_{\theta 3}=\left(\frac{\pi}{4} \omega N \eta+\frac{\partial M_{\theta}}{\partial \theta}\right) \theta_{0} \\
& M_{01}=-M_{04}=\left(\frac{\pi}{4} \omega N \eta-\frac{\partial M_{\theta}}{\partial \theta}\right) \theta_{0}
\end{aligned}
$$

$M_{0}$ shown in Fig. 4 can be obtained by connecting accumulators which have the pressure characteristics shown in Fig. 5, and the average delivery flow $Q$ from the cylinder is controlled in a quantity shown by Eq. (16).

$$
\mathrm{Q}=2 \theta_{\mathrm{a}} \mathrm{A}_{\mathrm{o}} \mathrm{r} / \mathrm{T}=\mathrm{D}_{\mathrm{m}} \mathrm{n} / \eta_{\mathrm{v}} \propto \overline{\mathrm{p}}
$$

then, displaccment $D_{m}$ of the motor becomes,

$$
\mathrm{D}_{\mathrm{m}}=\frac{2 \theta_{0} \mathrm{~A}_{\mathrm{p}} r \eta_{\mathrm{v}}}{\mathrm{T} \mathrm{n}}=\frac{8}{\pi} \cdot \frac{\left(\mathrm{A}_{\mathrm{Q}} \mathrm{r}\right)^{2}}{\operatorname{TnN} \omega} \cdot \frac{\eta_{\mathrm{v}}}{\eta} \overline{\mathrm{p}}
$$

where

where

$$
\bar{p}=\bar{M}_{\theta} / A_{p} r
$$




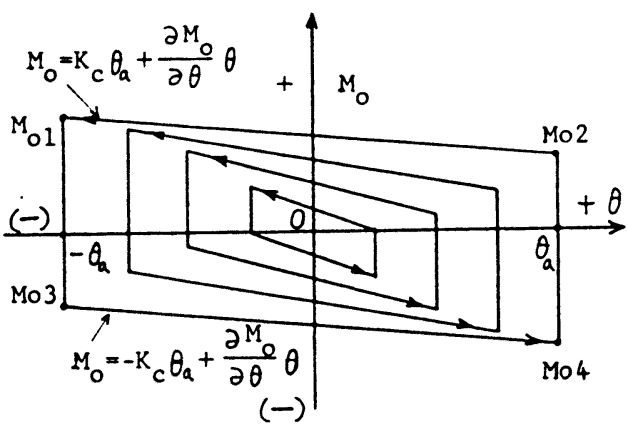

Fig. 4 Reaction Moment $M_{0}$

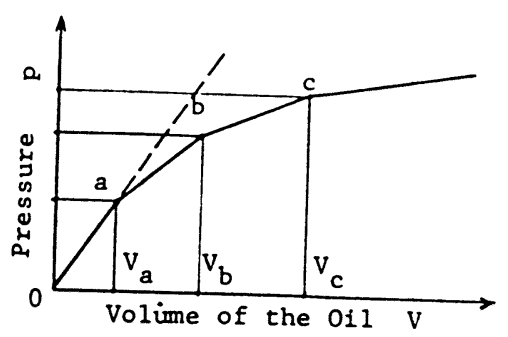

Fig. 5 Characteristics of the Accumulators

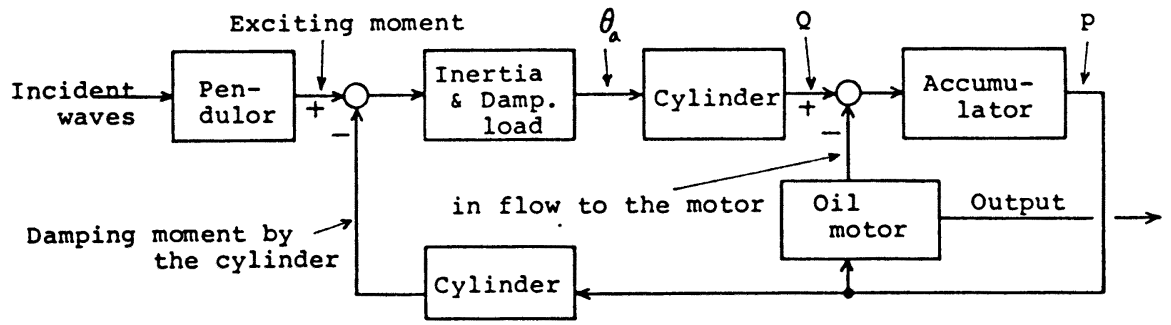

Fig. 6 Block Diagram of the Optimal operating System

SPECIFICATIONS

Incident Wave Power

Absorption Power

$=5 \mathrm{~kW}$

when $\mathrm{H}_{1 / 3}=1.5 \cdot \mathrm{m}$

$\mathrm{T}_{1 / 3}=4.0 \mathrm{~s}$

$\mathrm{h}=2.75 \mathrm{~m}$

Fig. 7 General View of the Test Pendulor

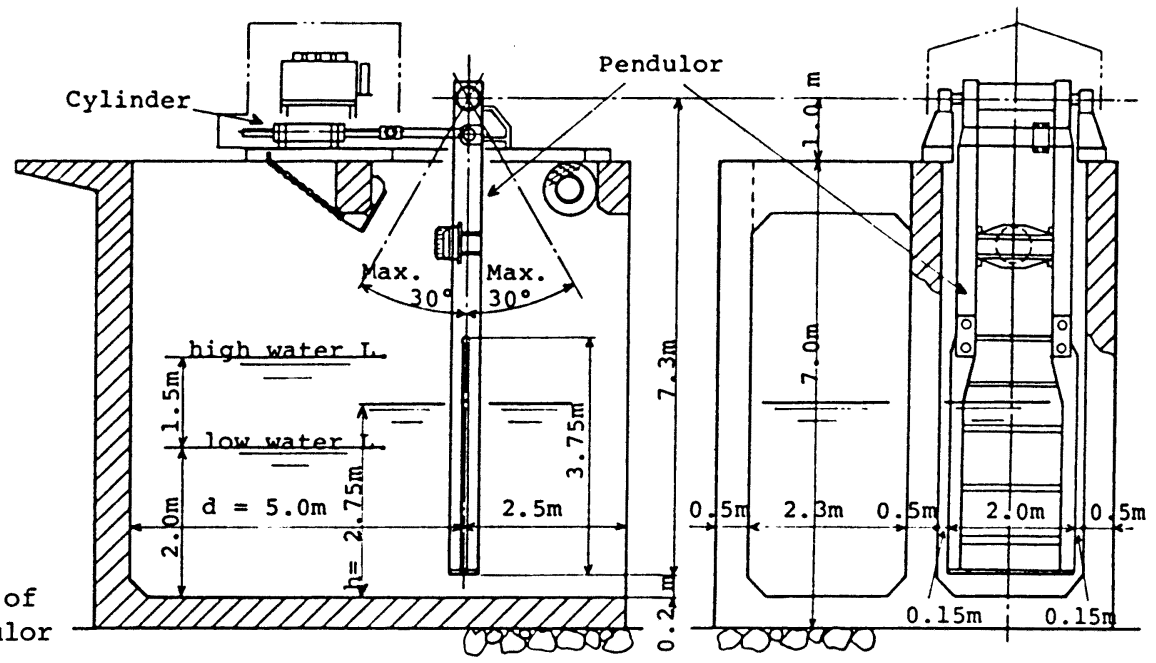

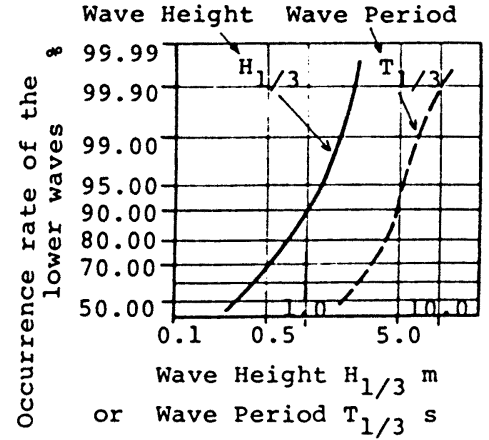

Fig. 8 The Wave Climate

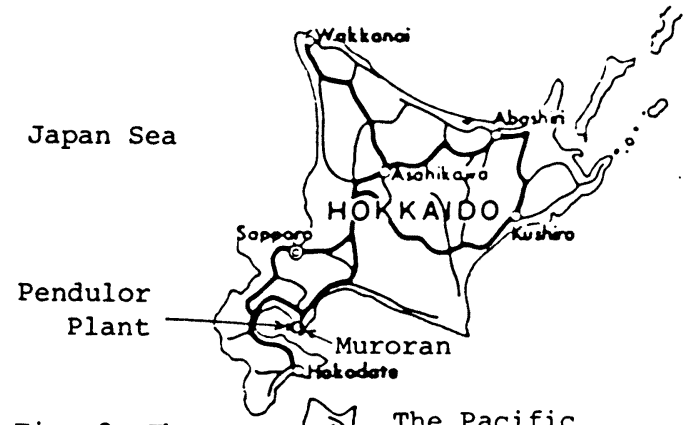

Fig. 9 The Location Site vamori 


$$
\bar{M}_{e}=\frac{1}{2}\left(M_{01}+M_{02}\right)
$$

Fig. 6 shows the principle of this optimal operation as a block diagram. When the motor drives a constant speed generator, the output is proportional to $i$ ts average torque $T_{m}$.

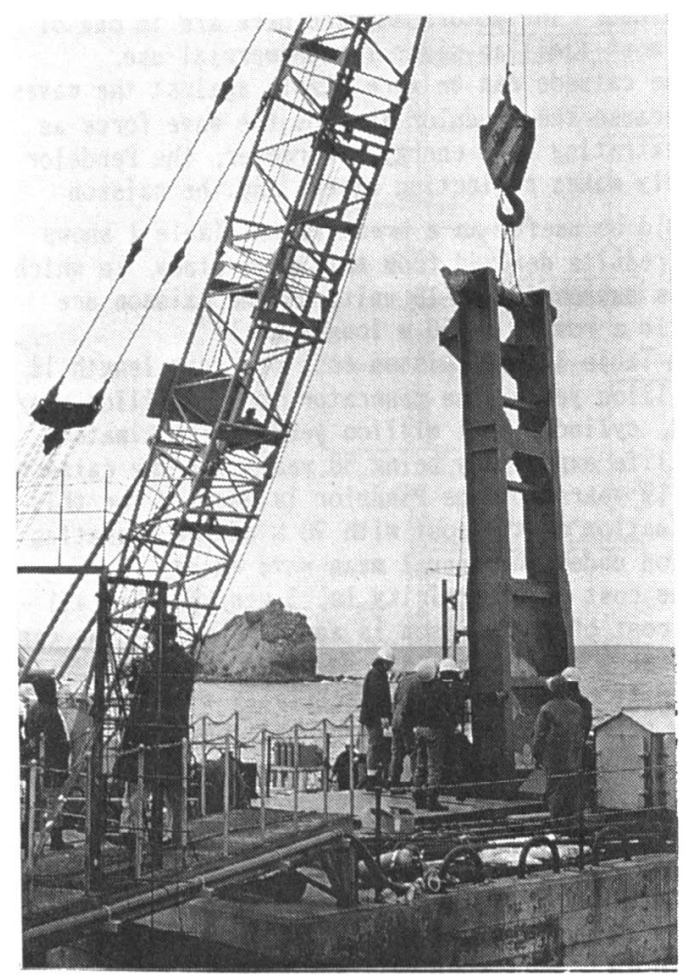

Fig. 10 Photo. of the Test Pendulor

$$
\begin{aligned}
T_{n} & =\frac{\bar{p} D_{m}}{2 \pi} \eta_{t} \\
& =\left(\frac{2}{\pi} \cdot A_{p} r \bar{p}\right)^{2}(T n N \omega)-1 \frac{\eta_{\square}}{\eta}
\end{aligned}
$$

There are two negative feed backs in Fig. 6; --flow of the motor and damping by the cylinder, so the output is balanced at a level tracing to the incident energy level.

This system needs no any complicated devices such as wave senser, computer etc. except only wave climate data observed at a near site where the Pendulor is placed.

\section{EXPERIMELNTAL OPERATION}

We made a Pendulor device illustrated Fig. 7 in which the main specifications are described there.

They were decided in terms of the wave climate data shown in Fig. 8 which were measured off shore one kilometer away from the experimental site. It is in front of an outer dike of Muroran Port faced to the bay of Uchiura ( See Fig. 9). Fig. 10 shows that the Pendulor is going to set at the site.

The Pendulor has been operating there since 1983 and Fig. 11 is a typical oscillogram recorded under as much the incident energy as 5 times level of the design point. In the Figure, cylinder pressure $P_{1}$ and $P_{2}$ appeared with two lines of saw edges-like, because of the accumulators of which the characteristics are similar to Fig. 4 and 5. In spite of a big fractuation of $P_{1}$ and $P_{2}$, the fractuation does not affect the output torque and the speed of the motor so much as seen in Fig. 11. The output of the motor was $18 \sim 35 \mathrm{~kW}$ ( on the average $24 \mathrm{~kW}$ ), while the incident wave power was about $55 \mathrm{kN}{ }^{9}$ )
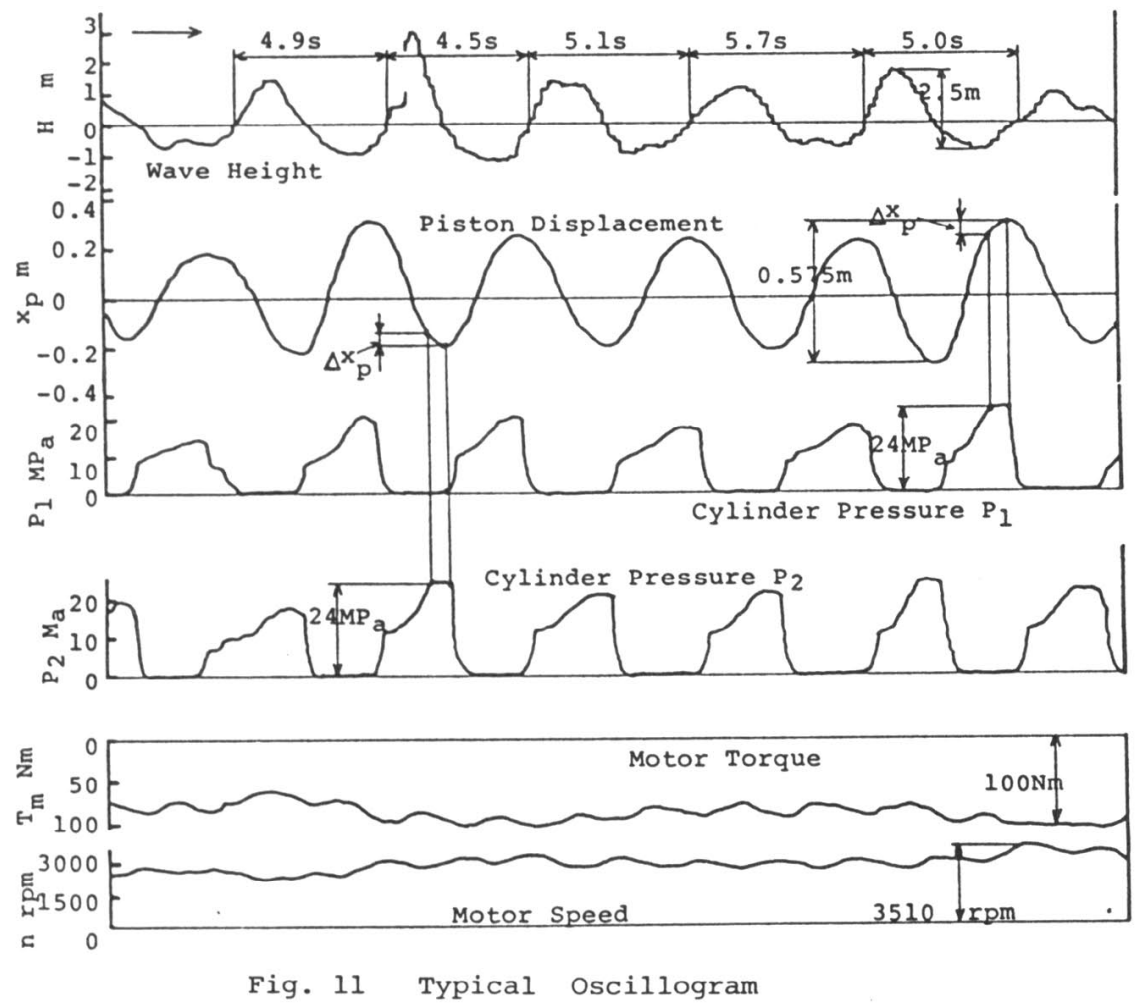
As explained preveously, the energy absorption ratio $\eta$ depends upon the period $T$ and the reaction moment $M_{B}$. Since the test Pendulor was designed to $T=4.0 \mathrm{~s}$, it can be resonated with waves having longer period than $4.0 \mathrm{~s}$. In fact, the Pendulor has proved its ratio $\eta$ high when $\mathrm{T} \geqq 4.0 \mathrm{~s}$.

Fig. 12 shows $\eta$ of the test Pendulor versus load ratio $N_{0} / N$, where $N_{8}$ means an equivalent linear damping coefficient by the cylinder,

$$
N_{\theta}=\frac{1}{T} \int_{0}^{T} \frac{M_{0}}{\dot{\theta}} \mathrm{d} t
$$

The energy absorption ratio $\eta$ was calculated using several measuring data, which have wave data more than 200 of the recording even at one measuring interval. Here $\eta$ is defined as Eq. (22)

$$
\eta=\frac{\frac{t_{\theta}}{t_{0} t_{0}^{t_{\theta}} M_{\theta} \dot{\theta} \mathrm{d} t}}{\mathrm{~PB}_{\mathrm{p}}}
$$

where $t_{0}$ is measuring inreval for a datum.

The Pendulor shows a peak in $\eta$ curve near $\mathrm{N}_{0} / \mathrm{N}=1$ portion where $n$ takes about $70 \%$ The white circles in Fig. 12 are in the case that $M_{8}$ is similar to Fig. 4, ${ }^{10}$, and they are better than black cirles.

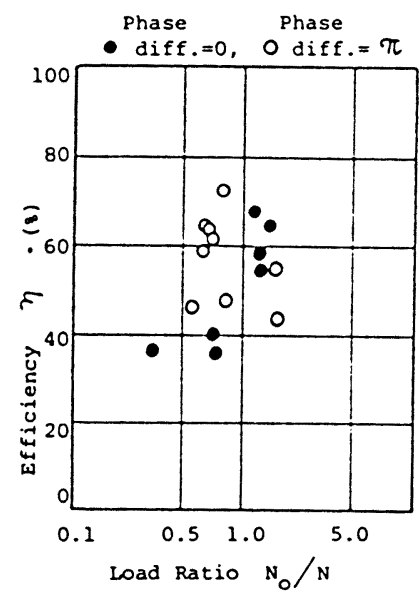

Fig. 12 Wave Power Absorption Ratio

\section{A STUDY ON COST EXPECTANCY}

Considering cost efficiency, the apparatuses must be installed at the sites where they can get some economic merits because of its good energy density. For instance, the coastline faced to Norwegian sea in Europe and the places around Cape Town in Southern Africa have as much annual mean energy flux as $20 \sim 40 \mathrm{~kW} / \mathrm{m}^{1}$ "1) However, we tried to make a design of a proto-type Pendulor for the cost study. Fig. 13 and 14 show the hydraulic circu its and the general view of the proto-type Pendulor. In this case, $10.6 \mathrm{k} / \mathrm{m}$ was adopted as the annual mean energy flux corresponding to with $\mathrm{H}_{1,3}=2 \mathrm{~m}$ and $\mathrm{T}_{1,3}=6 \mathrm{~s}$.
A 25 mide caisson is used as a unit and three water chambers including a 7 mide Pendulor each in it are prepared. So the total wave power coming into a unit becomes $222 \mathrm{~kW}$, and the output; $88 \mathrm{~kW}$ of electric power, can be estimated adopting $\eta=40 \%$ to the case of an annual mean power. The capacity of the generator being $90 \mathrm{~kW}$ for rating and $150 \mathrm{k}$ for peak has been selected in Fig. 13 \& 14. In order to drive the generator, 6 H.S.T. units combined with cylinders and motors are provided. The motors adopted here are in one of the most familiar sizes for commercial use.

The caisson can be more stable against the waves , because the Pendulor absorbs the wave force as an extrating wave energy. Moreover, the Pendelor hardly makes reflecting waves, and the caisson should be useful as a breakwater. Table 1 shows the results derived from this case study, in which it is supposed that 10 units of the caisson are set in a row as a $250 \mathrm{~m}$ long dike. ${ }^{12}$ )

In Table 1, the caisson cost per unit length is $6 \mathrm{million}$ yen/m, the generator is 8.5 million yen/ unit, cylinder is 1 million yen/u are estimated. The life expectancy being 50 years for the caisson and 15 years for the Pindulor is adopted for this estimation of the cost with $90 \%$ of the operating period under the annual mean wave energy.

The cost of electricity is $25 \mathrm{yen} / \mathrm{k}$ WH when all the cost of the caisson is added to it. If we can utilize a breakwater as a facility of power generation, the cost of electricity will reach a very attractive level without the cost of caisson; --- $9.4 \mathrm{yen} / \mathrm{k}$ HH would be predicted.

\section{CONCUUSIONS}

By combining with a mechanical and oil-hydraulic technology, more adaptable and more flexible systems become feasible to utilize ocean wave power - The Pendulor is an example.

The optimal conditions of the Pendulor are expressed as follows

(1) the Pendulor is placed at the node,

(2) load ratio $N_{0} / N \fallingdotseq 1$,

(3) the Pendulor is driven at the resonance.

Maximum value of the absorption ratio obtained by the experiments is $70 \%$ with both model and plant tests.

The Pendulor improves the stability of caisson and the reflecting waves.

Cost of electricity generated by a 250 m long caisson ( attaching the Pindulors), would expect 25 yen / kWH or 9.4 yen / kWH with or without caisson cost, when the system is driven by the waves having an annual mean energy flux $=10.6$ $\mathrm{kW} / \mathrm{m}$

We have already patented the Pendulor system in UK, USA, Canada and Japan.

\section{ACKNONLEDGEMENT}

The authors are extremely thankful to the old students who had worked with us for a long time as our members.

Major part of the present study has been supported by Science Research Fund of the Ministry of Education. 


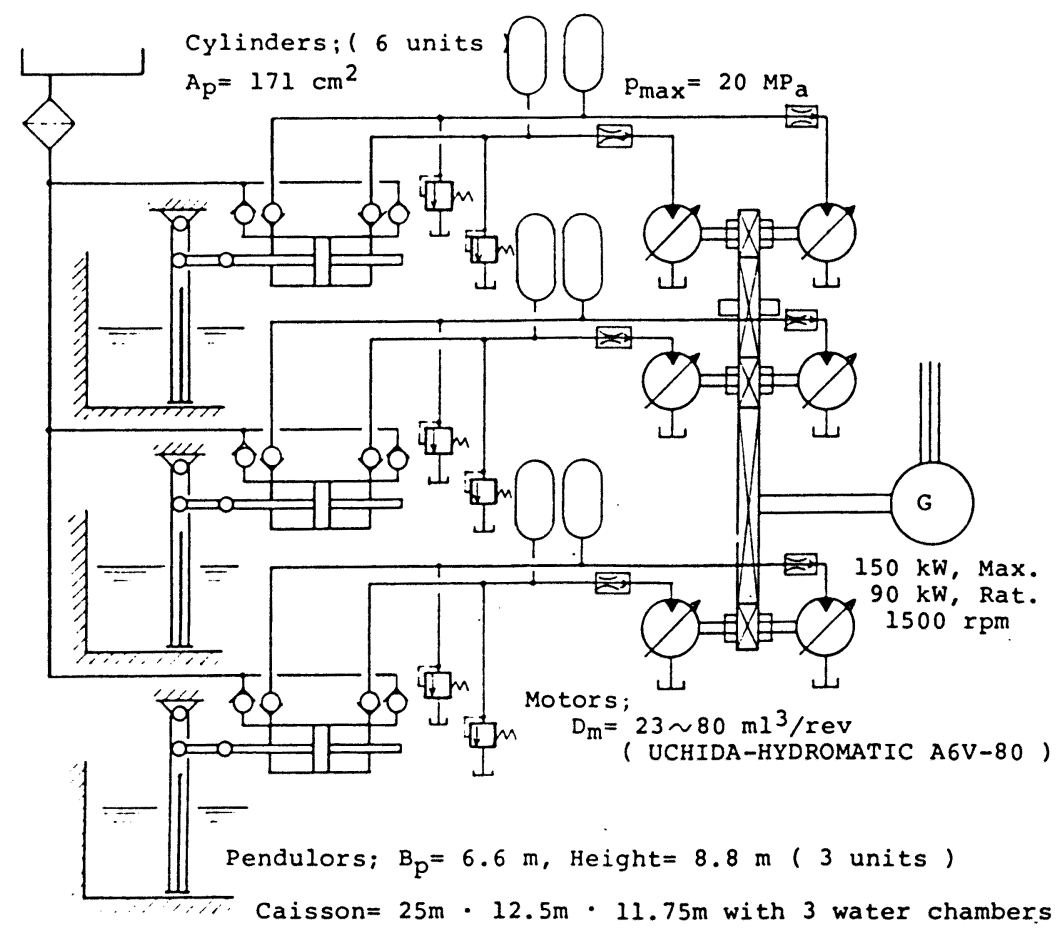

Fig. 13 Hydraulic Circuits of the Proto-type Pendulor System

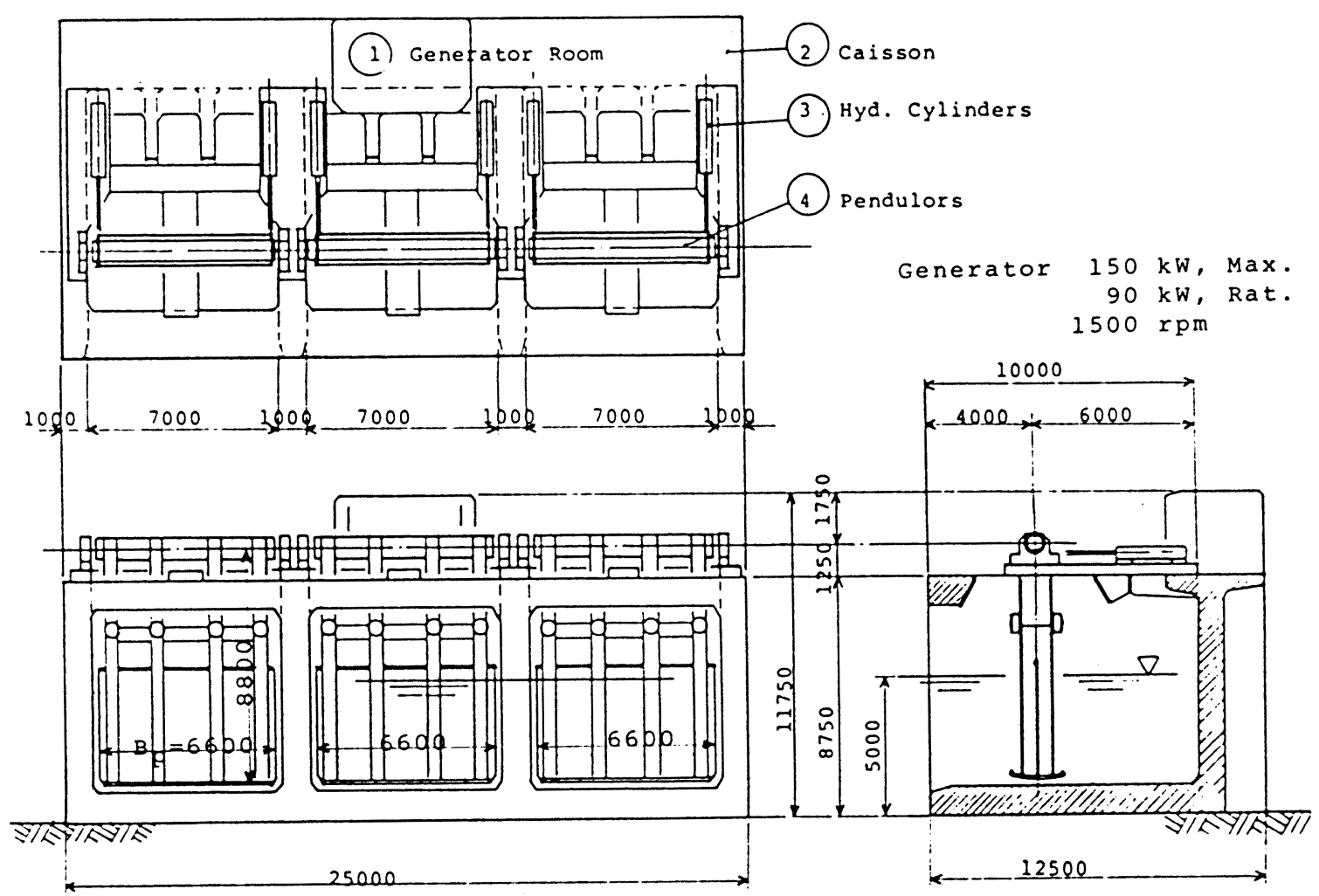

Fig. 14 General View of the Proto-type Pendulor System 
Table 1 Cost of Electricity Generated by the Pendulor

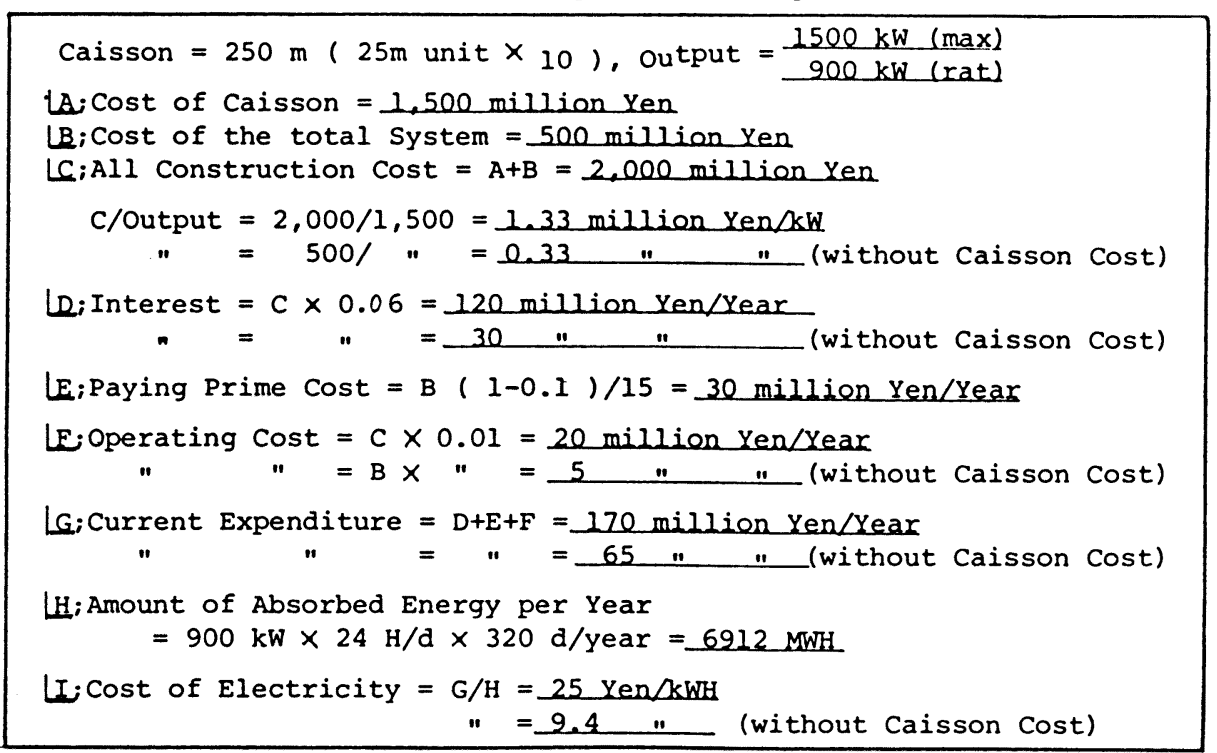

\section{REFERENCES}

1. T. Natabe, Nave power utilization, Journal of JHPS, Vol. 17, No. 7, 1986 ( in Japamese)

2, T. Natabe, H. Kondo \& K. Yano, Studies on a Pendulor-type wave energy converter, proc. 3 rd int. sym. water for Energy, BHPA, 1986

3, T. Natabe et al, Method \& apparatus for generating electric power by waves, U.S.A. Patent 4, 490, 621, 1984

4. T. Natabe, Studies on the Pendulor-Type wave energy converter; A consideration of the optimal operation (I) proc. of JSME No. 880-1, the 65th JSME gen. conf., 1988 ( in Japanese )

5. T. Natabe, H. Kondo \& K. Yano, A feasible studly on a Pendulor system, proc. of the 2 nd sym. on wave energy utilization in Japan, JMSTC, 1987 ( in Japanese )

6. S. Asano, Studies on power absorption ratio of a Pendulor, report II div. in water vessel comittee, the JSSB, SK 60-14, 1980 ( in Japanese )

7. H. Kondo \& H. Takeda, Nave energy dissipating structures, Morikita Book Co., 1983 ( in Japanese)

8. S. Asano \& T. Natabe, A theoretical study of a Pendulor-type wave energy converter, report of Muroran Institute of Tech., 1986

9. T. Katabe, H. Kondo \& K. Yano, Studies on a Pindulor: the 1st experimental operation by Muroran Plant, JSME paper (B) Vol.51, No.466, 1985 ( in Japanese)

10. T. Natabe, Y. Kubota, H. Sugi yama \& H. Kondo, Studies on a Pendulor; conversion loss by the system's elasticity \& its counter methods, JSME paper (B) Vol.54, No. 500. 1988 ( in Japanese)

11, G. Retief \& F. Mü ller, Wave energy potential of Southern Africa, national conf. on renewable resources in Cape Town, 1986

12. T. Natabe, H. Kondo \& M. Kobitama, Studies on the utilization of wave energy for remote islands; a case study of Yagishiri Island, a study report on energy problems on human society \& economy, JME, 1988 ( in Japanese ) 